\title{
Evaluation of recombinant activated protein $C$ for severe sepsis at a tertiary academic medical center
}

This article was published in the following Dove Press journal:

Therapeutics and Clinical Risk Management

4 June 2013

Number of times this article has been viewed

\author{
Kevin E Anger ${ }^{\prime}$ \\ Jeremy R DeGrado' \\ Bonnie C Greenwood' \\ Steven A Cohen ${ }^{2}$ \\ Paul M Szumita' \\ 'Department of Pharmacy, Brigham \\ and Women's Hospital, Boston, MA, \\ USA; ${ }^{2}$ Department of Family Medicine \\ and Population Health, Division of \\ Epidemiology, Virginia Commonwealth \\ University, Richmond, VA, USA
}

Correspondence: Kevin E Anger Brigham and Women's Hospital, Department of Pharmacy, Pharmacy Administration; L-2, 75 Francis Street, Boston, MA 02II5, USA

Tel +I 6177327677

Fax + I 6175662396

Email kanger@partners.org
Purpose: Early clinical trials of recombinant human activated protein C (rhAPC) for severe sepsis excluded patients at high risk of bleeding. Recent literature suggests bleeding rates are higher in clinical practice and may be associated with worsened outcomes. Our objective was to evaluate baseline demographics; incidence, and risk factors for major bleeding; and mortality of patients receiving rhAPC for severe sepsis at our institution.

Methods: A retrospective study was performed for all patients receiving rhAPC for treatment of severe sepsis at a tertiary academic medical center from January 2002 to June 2009. Demographic information, clinical variables, intensive care unit, and hospital outcomes were recorded.

Results: Of the 156 patients that received rhAPC, 54 (34.6\%) did not meet institutional criteria for safe use at baseline due to bleeding precaution or contraindication. Twenty-three $(14.7 \%)$ patients experienced a major bleeding event. Multivariate analysis demonstrated baseline International Normalized Ratio $\geq 2.5$ (odds ratio [OR] 3.68, 95\% confidence interval [CI]: $1.28-10.56 ; P=0.03)$ and platelet count $\leq 100 \times 10^{3} / \mathrm{mm}^{3}(\mathrm{OR} 2.86,95 \% \mathrm{CI}: 1.07-7.67 ; P=0.01)$ as significant predictors of a major bleed. Overall hospital mortality was $57.7 \%$. Multivariate analysis demonstrated the presence of $\geq 3$ organ dysfunctions (OR 2.46, 95\% CI: 1.19-5.09; $P<0.05$ ) and medical intensive care unit admission (OR 1.99, 95\% CI: 1.00-3.98; $P=0.05$ ) were independent variables associated with hospital mortality.

Conclusion: Patients receiving rhAPC at our institution had higher APACHE II scores, mortality, and major bleeding events than published postmarketing studies. Risk factors for major bleeding other than package-labeling contraindications and bleeding precautions were identified in our patient population.

Keywords: severe sepsis, activated protein C, drotrecogin alfa, Xigris

\section{Introduction}

Despite advances in best practices for the management of sepsis, mortality rates remain high as institutions seek to implement sepsis bundle therapy into clinical practice..$^{1-4}$ Activated protein $\mathrm{C}$ has long been identified as an important endogenous modulator involved in microvascular end-organ dysfunction in sepsis and low levels have been associated with worsened outcomes..$^{5-7}$ Activated protein $\mathrm{C}$ exhibits anticoagulant properties through inhibition of factors Va and VIIIa, profibrinolytic properties through its ability to inhibit plasminogen activator inhibitor-1 and decrease production of thrombin-activatable fibrinolysis inhibitor, and anti-inflammatory properties by decreasing release of tumor necrosis factor. ${ }^{8,9}$

Based upon the results of the Recombinant Human Activated Protein C Worldwide Evaluation in Severe Sepsis Trial (PROWESS) study, recombinant human activated 
protein $\mathrm{C}$ (rhAPC) has continued as a recommended therapeutic modality for select subgroups of patients in the Surviving Sepsis Campaign guidelines. ${ }^{1,10,11}$ Recent analysis examining the use of rhAPC in the clinical practice setting suggest higher bleeding event rates compared to analysis used in collaboration with the manufacturer. ${ }^{1,10-19}$ Post PROWESS data resulted in changes to package-labeling precautions and contraindications seeking to promote safe use of rhAPC in the clinical practice setting. Differences in patient demographics and risk factors for bleeding between randomized controlled trials (RCTs) and published analyses examining real-world use of rhAPC have resulted in concerns regarding the efficacy and safety of this agent. ${ }^{19,20}$ Results of Phase IV studies resulted in further calls for another placebo-controlled trial in patients with septic shock. ${ }^{11,21,22}$ The findings of the Prospective Recombinant Human Activated Protein C Worldwide Evaluation in Severe Sepsis and Septic Shock (PROWESS-SHOCK) trial resulted in the voluntary removal of rhAPC from the market by the manufacturer, however return of the agent to the market is still possible. ${ }^{23}$ Changes to efficacy and safety data warrant evaluation of practice parameters used to promote safe and efficacious use of rhAPC in the inpatient setting.

Prescribing of rhAPC at our institution is regulated by a local guideline developed using data from package labeling to promote safe and effective use. ${ }^{10,24,25}$ Given recently published data and changes to package labeling concerning the efficacy and safety of rhAPC, we undertook this analysis to evaluate prescribing practices and outcomes of patients receiving rhAPC therapy for severe sepsis at our institution since its United States Food and Drug Administration approval in 2001 .

\section{Materials and methods Design and setting overview}

A retrospective review of all patients who received rhAPC from January 2002 to June 2009 at Brigham and Women's Hospital was conducted. Brigham and Women's Hospital is a 777-bed tertiary academic medical center with 100 adult intensive care unit (ICU) beds.

A list of all patients prescribed rhAPC was obtained from an electronic database within our computerized provider order entry system (CPOE). Patients who received at least 1 hour of rhAPC were eligible for inclusion in the analysis. Patients were excluded if they lacked adequate medical record availability. Prescribing of rhAPC at our institution has been guided by an institutional guideline with CPOE decision support since its United States release. ${ }^{24}$ Institutional criteria for rhAPC requires patients to have the presence of a likely or known infection as well as three of the four Systemic Inflammatory Response Syndrome criteria. ${ }^{24}$ Patients are also required to have acute dysfunction of at least one organ system and an Acute Physiology and Chronic Health Evaluation II (APACHE II) score $\geq 25$. Relative contraindications to rhAPC at our institution include the following package-labeling contraindications and bleeding precautions; current pharmacologic anticoagulation, active bleeding or coagulopathy (prothrombin time-International Normalized Ratio [INR] $>3.0$ ), platelet count $<30,000 / \mathrm{mm}^{3}$, recent major surgery, recent hemorrhagic stroke, cranial or spinal procedure, head trauma, trauma with increased bleeding risk, presence of an epidural catheter, or an intracranial mass or neoplasm. ${ }^{24}$ Patients that did not meet institutional criteria due to a relative contraindication or APACHE II criteria could still receive rhAPC if an attending physician overrode the institutional criteria after specialist consultation. ${ }^{24}$

\section{Outcomes and follow-up}

Outcomes included prescribing according to institutional criteria, duration of rhAPC infusion, transfusion requirements (packed red blood cells, platelets, and fresh frozen plasma), length of stay, mortality, incidence of major bleeding, and discontinuation of rhAPC therapy due to bleeding or coagulopathy. Major bleeding criteria required patients to meet at least one of three objective criteria, plus documentation of bleeding in the medical record by the physician or nurse in a daily progress note, discharge summary, or autopsy report. ${ }^{17}$ Objective criteria was defined as: (a) an acute $(<48$ hour) drop in hemoglobin of $\geq 2 \mathrm{~g} / \mathrm{dL}$; (b) transfusion requirement of $\geq 4$ units of packed red blood cells in 48 hours; or (c) objective evidence of bleeding that resulted in prolonged hospitalization, death, or other adverse outcome. Major bleeding was assessed while the patient was receiving rhAPC and for 24 hours after discontinuation.

\section{Statistical analysis}

Statistical analysis of patients receiving rhAPC was conducted using SPSS software (version 17.0; IBM, Armonk, NY, USA). Patient demographics, treatment characteristics, and outcomes were described using measures of central tendency or proportions with measures of variance as appropriate. A priori subgroups were identified based upon in hospital mortality and major bleeding events. Demographic and treatment variables were compared between survivors and nonsurvivors and between those who experienced a major bleeding event and those who did not using Student's $t$-test or Mann-Whitney $U$-test for continuous variables and Chi-square tests for ordi- 
nal data. Type I error rate $(\alpha)$ level was set at $\leq 0.05$. Odds ratios (OR) and $95 \%$ confidence intervals $(95 \% \mathrm{CI})$ for independent variables were calculated. Simple logistic regression was used to estimate the ORs for individual predictors of the outcomes of interest. Variables found to be significantly different $(\alpha=0.05)$ were then modeled using forward multivariate stepwise logistic regression to determine independent variables associated with major bleeding events or hospital mortality. These logistic regression models were assessed for goodness-of-fit using $-2 \mathrm{log}$ likelihood ratios for models where the total sample size was equal across models. Interaction terms were not tested for in this analysis. The protocol was reviewed and approved by the Brigham and Women's Hospital/Partners Institutional Review Board prior to data collection.

\section{Results}

\section{Patients}

A total of 190 patients were ordered for rhAPC from January 2002 to June 2009. Thirty-four patients were excluded from the analysis for incomplete medical records $(n=6)$ or failure to receive at least 1 hour of infusion due to death/withdrawal of care $(n=28)$. The remaining 156 patients that received rhAPC were included in the analysis. The distribution of patients receiving rhAPC per year is shown in Figure 1, with use declining after peaking in 2003. Of the 156 patients receiving rhAPC therapy, 54 (34.6\%) did not meet institutional criteria for safe use at baseline due to precaution or contraindication. Of the 54 patients that did not meet institutional criteria, 49 (91\%) had a baseline bleeding precaution and $5(9 \%)$ had a contraindication to therapy according to package labeling. The most common reasons for not meeting institutional criteria were surgery within 12 hours and active bleed or coagulopathy.

Baseline demographic data is presented in Table 1. The majority of patients receiving rhAPC were admitted to a surgical or burn/trauma (54\%) ICU. The mean APACHE II score was $29.6 \pm 5.8$. Pneumonia (38\%) and intra-abdominal (29\%) infections were the primary sources of sepsis. The average duration of rhAPC therapy was $67.8 \pm 36$ hours. Seventy-five patients $(48.1 \%)$ had rhAPC discontinued before 96 hours, with $37(23.7 \%)$ due to death or withdrawal of treatment, $20(12.8 \%)$ attributed to a bleeding event or coagulopathy, $8(5.1 \%)$ due to surgery or procedure, $4(2.6 \%)$ due to transfer to a stepdown unit or rapid clinical improvement, 2 (1.2\%) due to acute myocardial infarction or pulmonary embolism requiring anticoagulation, $2(1.2 \%)$ due to infusion duration documentation error, and $2(1.2 \%)$ for change to nonsepsis diagnosis.

Mean ICU and hospital length of stay was 20 and 27 days, respectively. A total of 117 patients (75\%) required transfusion of a blood product while on rhAPC therapy. Mean consumption on blood products per patient on rhAPC therapy was 1.5 units of packed red blood cells, 0.7 units of platelets, and 1.9 units of fresh frozen plasma.

\section{Analysis of major bleeding}

Twenty-three of the 156 patients (14.7\%) experienced a major bleeding event, all of which occurred during the infusion. The number of patients meeting each objective criteria for major bleeding was: acute drop in hemoglobin $(n=15)$, transfusion requirement $(\mathrm{n}=4)$, and objective evidence of bleeding

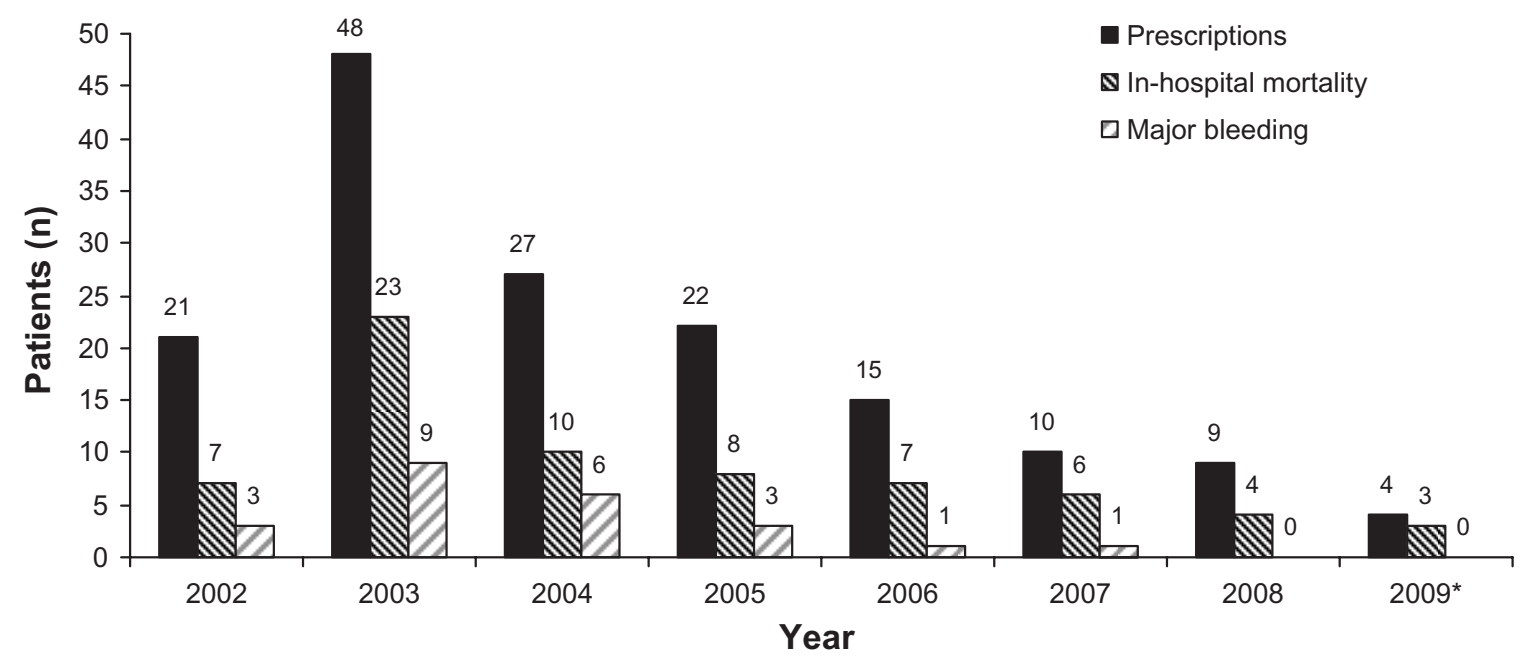

Figure I Patients receiving activated protein C, in-hospital mortality, and major bleeding event by year. Note: *Data for 2009 is through the month of June. 
Table I Demographic data at initiation of recombinant human activated protein C

\begin{tabular}{|c|c|}
\hline Variable & $\begin{array}{l}\text { Overall } \\
(n=156)\end{array}$ \\
\hline Age, years* & $61 \pm 16.8$ \\
\hline Male, n (\%) & $91(58)$ \\
\hline APACHE II* & $29.6 \pm 5.8$ \\
\hline \multicolumn{2}{|l|}{ New organ failure, $n(\%)$} \\
\hline Cardiovascular & $146(94)$ \\
\hline Respiratory & $102(65)$ \\
\hline Renal & $104(67)$ \\
\hline Hematologic & $36(23)$ \\
\hline Metabolic & $94(60)$ \\
\hline Organ dysfunctions* & $3.1 \pm 1.1$ \\
\hline \multicolumn{2}{|l|}{ ICU type, n (\%) } \\
\hline Medical & $72(46)$ \\
\hline Surgical/trauma & $84(54)$ \\
\hline Baseline precaution or contraindication, $n(\%)^{\dagger}$ & $54(34.6)$ \\
\hline \multicolumn{2}{|l|}{ Infection site, $\mathrm{n}(\%)$} \\
\hline Pneumonia & $60(38)$ \\
\hline Intra-abdominal & $45(29)$ \\
\hline Skin & $25(16)$ \\
\hline Urological & $12(8)$ \\
\hline Other/unknown & $14(9)$ \\
\hline \multicolumn{2}{|l|}{ Pathogen, n (\%) } \\
\hline Gram positive & $40(26)$ \\
\hline Gram negative & $42(27)$ \\
\hline Fungal & $6(4)$ \\
\hline Mixed & $8(5)$ \\
\hline Other/unknown & $60(38)$ \\
\hline Corticosteroids, n (\%) & $89(57)$ \\
\hline Vasoactive agent infusion ${ }^{\dagger+*} *$ & $2.1 \pm 1$ \\
\hline CRRT, n (\%) & $40(26)$ \\
\hline Mechanical ventilation, n (\%) & $143(92)$ \\
\hline Platelets, $\times 10^{3} / \mathrm{mm}^{3 *}$ & $180 \pm 112$ \\
\hline INR* & $2.0 \pm 1.0$ \\
\hline VTE prophylaxis, n (\%) & $28(18)$ \\
\hline
\end{tabular}

Notes: *Data presented as mean \pm standard deviation; ${ }^{\text {taccording }}$ to package labeling and institutional guidelines; ${ }^{\dagger}$ vasoactive agents include: Norepinephrine, phenylephrine, epinephrine, vasopressin, dopamine, and dobutamine. Corticosteroid use was defined as administration of at least $100 \mathrm{mg}$ of hydrocortisone equivalents in the first 24 hours of ICU admission. VTE prophylaxis included use of unfractionated heparin or low molecular weight heparin at doses recommended for prophylaxis according to the American College of Chest Physicians Eighth Conference Evidence Based Guidelines.

Abbreviations: APACHE, Acute Physiology and Chronic Health Evaluation; ICU, intensive care unit; CRRT, continuous renal replacement therapy; INR, International Normalized Ratio; VTE, venous thromboembolism.

$(n=6)$. Primary sites of bleed included: 8 gastrointestinal, 5 hematoma, 4 surgical site, 3 vascular access, 1 urinary, 1 central nervous system (CNS), and 1 intra-abdominal. One patient died of an intra-cranial hemorrhage during the infusion. Yearly major bleeding rates ranged from $6.7 \%$ to 22.2\% between 2002 and 2007, with no events in the last 18 months of the analysis (Figure 1).

Patients experiencing major bleed had a lower mean baseline platelet count $\left(129 \pm 105\right.$ vs $189 \pm 111 \times 10^{3} / \mathrm{mm}^{3}$;
$P=0.02)$ and higher baseline INR $(2.5 \pm 1.2$ vs $1.9 \pm 0.9$; $P=0.03)$ than those who did not bleed. Baseline platelet counts $\leq 100,000 / \mathrm{mm}^{3}$ (48\% vs $\left.23 \% ; P=0.01\right)$, INR values $\geq 2.0(61 \%$ vs $29 \% ; P<0.01)$, APACHE II score $\geq 30$ (74\% vs 44\%; $P=0.02$ ), and medical ICU admission (65\% vs $43 \% ; P=0.05$ ) were more likely to be seen in patients experiencing a major bleed (Table 2). Multivariate logistic regression analysis identified baseline INR values $\geq 2.5$ (OR 3.68, 95\% CI: $1.28-10.56 ; P=0.03$ ) and platelet count $\leq 100,000 / \mathrm{mm}^{3}$ (OR 2.86, 95\% CI: 1.07-7.67; $P=0.01)$ as significant predictors of a major bleed. No significant difference in the use of pharmacological venous thromboembolism prophylaxis $(17 \%$ vs $18 \% ; P=0.94)$, hospital mortality $(65.2 \%$ vs $56.4 \% ; P=0.43)$, or hospital length of stay $(22.5 \pm 24$ vs $28 \pm 29$ days; $P=0.33)$ was seen in patients experiencing a major bleeding event. Administration

Table 2 Univariate analysis of major bleeding events

\begin{tabular}{|c|c|c|c|}
\hline Variable & $\begin{array}{l}\text { Major } \\
\text { bleed } \\
(n=23)\end{array}$ & $\begin{array}{l}\text { No major } \\
\text { bleed } \\
(n=133)\end{array}$ & $P$ value \\
\hline Hemoglobin, g/dL* & $9.9 \pm 1.6$ & $10.3 \pm 1.6$ & 0.28 \\
\hline Platelets, $\times 10^{3} / \mathrm{mm}^{3 *}$ & $129 \pm 105$ & $189 \pm 111$ & 0.02 \\
\hline$\leq 100, \mathrm{n}(\%)^{\dagger}$ & II (48) & $30(23)$ & 0.01 \\
\hline$\leq 50, \mathrm{n}(\%)$ & $5(22)$ & $4(3)$ & $<0.01$ \\
\hline INR* & $2.5 \pm 1.2$ & $1.9 \pm 0.9$ & 0.03 \\
\hline INR $\geq 2.0, \mathrm{n}(\%)$ & $14(61)$ & $39(29)$ & $<0.01$ \\
\hline INR $\geq 2.5, \mathrm{n}(\%)^{\dagger}$ & $9(39)$ & $16(12)$ & $<0.01$ \\
\hline INR $\geq 3.0, \mathrm{n}(\%)$ & $5(22)$ & $10(7.5)$ & 0.03 \\
\hline INR $\geq 3.5, \mathrm{n}(\%)$ & $4(17)$ & $8(6)$ & 0.06 \\
\hline APACHE II* & $31.1 \pm 5.8$ & $29.4 \pm 5.7$ & 0.2 \\
\hline $0-19$, n (\%) & I (4) & $3(2)$ & 0.56 \\
\hline $20-24, \mathrm{n}(\%)$ & I (4) & $13(10)$ & 0.4 \\
\hline $25-29$, n (\%) & $5(22)$ & $58(44)$ & 0.05 \\
\hline$\geq 30, \mathrm{n}(\%)$ & $16(74)$ & $58(44)$ & 0.02 \\
\hline Organ dysfunctions* & $3.3 \pm 1$ & $3.1 \pm 1.1$ & 0.39 \\
\hline $\begin{array}{l}\text { Package label precaution } \\
\text { or contraindication, n (\%) }\end{array}$ & $16(70)$ & $86(65)$ & 0.65 \\
\hline CRRT, n (\%) & $9(39)$ & $31(23)$ & 0.1 \\
\hline VTE prophylaxis, n (\%) & $4(17)$ & $24(18)$ & 0.94 \\
\hline Medical ICU, n (\%) ${ }^{\dagger}$ & $15(65)$ & $57(43)$ & 0.05 \\
\hline Surgical ICU, n (\%) & $8(35)$ & $76(57)$ & 0.05 \\
\hline Packed red blood cells & $2.5 \pm 2.5$ & $1.3 \pm 1.7$ & 0.04 \\
\hline Platelets & $2.3 \pm 4.4$ & $0.4 \pm 1.5$ & 0.06 \\
\hline FFP & $5.9 \pm 12$ & $1.2 \pm 2.5$ & 0.08 \\
\hline ICU length of stay; days* & $18.1 \pm 20$ & $20.1 \pm 24.1$ & 0.67 \\
\hline Hospital length of stay; days* & $22.5 \pm 24$ & $28 \pm 29$ & 0.33 \\
\hline ICU mortality, n (\%) & $15(65.2)$ & $69(51.9)$ & 0.24 \\
\hline Hospital mortality, n (\%) & $15(65.2)$ & $75(56.4)$ & 0.43 \\
\hline
\end{tabular}

Notes: *Data presented as mean $\pm \mathrm{SD}$; ${ }^{\dagger}$ variable selected for the multivariate logistic regression analysis.

Abbreviations: INR, International Normalized Ratio; APACHE, Acute Physiology and Chronic Health Evaluation; CRRT, continuous renal replacement therapy; FFP, Fresh frozen plasma; VTE, venous thromboembolism; ICU, intensive care unit; SD, standard deviation. 
of blood products was more common in patients experiencing major bleed.

\section{Analysis of mortality}

Overall ICU and in-hospital and ICU mortality was 53.8\% and $57.7 \%$, respectively. Yearly in hospital mortality rates ranged from $33.3 \%$ to $75 \%$ between 2002 and 2009 (Figure 1). Patients experiencing in hospital mortality on average were older (65.2 \pm 17 vs $55.4 \pm 15.4$ years; $P<0.01)$, required more vasoactive agents $(2.4 \pm 1$ vs $1.8 \pm 1$ agents; $P<0.01)$,

Table 3 Univariate analysis of baseline data and outcomes of patients with or without in hospital mortality

\begin{tabular}{|c|c|c|c|}
\hline Variable & $\begin{array}{l}\text { Mortality } \\
(n=90)\end{array}$ & $\begin{array}{l}\text { No } \\
\text { mortality } \\
(n=66)\end{array}$ & $P$ value \\
\hline Age* & $65.2 \pm 17$ & $55.4 \pm 15.4$ & $<0.01$ \\
\hline Vasoactive agent & $2.4 \pm 1$ & $1.8 \pm 1$ & $<0.01$ \\
\hline \multicolumn{4}{|l|}{ infusion; days* } \\
\hline Organ dysfunctions* & $3.3 \pm 1.1$ & $2.9 \pm 1.2$ & 0.04 \\
\hline I, n (\%) & $2(2)$ & $4(6)$ & 0.22 \\
\hline $2, \mathrm{n}(\%)$ & $20(22)$ & $26(39)$ & 0.02 \\
\hline $3, \mathrm{n}(\%)$ & $30(33)$ & I8 (27) & 0.42 \\
\hline $4, \mathrm{n}(\%)^{\dagger}$ & $26(29)$ & $10(15)$ & 0.05 \\
\hline $5, \mathrm{n}(\%)$ & $12(13)$ & $8(12)$ & 0.82 \\
\hline APACHE II* & $30.8 \pm 5.3$ & $28 \pm 6$ & $<0.01$ \\
\hline $0-19$, n (\%) & $\mathrm{I}(\mathrm{I})$ & $3(5)$ & 0.18 \\
\hline 20-24, n (\%) & $5(6)$ & $9(14)$ & 0.08 \\
\hline 25-29, n (\%) & $34(38)$ & $29(44)$ & 0.44 \\
\hline$\geq 30, \mathrm{n}(\%)^{\dagger}$ & $50(56)$ & $25(38)$ & 0.03 \\
\hline Presence of any & $35(39)$ & $19(29)$ & 0.19 \\
\hline \multicolumn{4}{|l|}{ baseline precaution } \\
\hline \multicolumn{4}{|l|}{ or contraindication, $\mathrm{n}(\%)$} \\
\hline CRRT, n (\%) & $28(3 \mathrm{I})$ & $12(18)$ & 0.07 \\
\hline Mechanical ventilation, n (\%) & $84(93)$ & $59(89)$ & 0.38 \\
\hline Corticosteroids, n (\%) & $55(61)$ & $34(52)$ & 0.23 \\
\hline \multicolumn{4}{|l|}{ Infection type; n (\%) } \\
\hline Pneumonia & $39(43)$ & $21(32)$ & 0.15 \\
\hline Intra-abdominal & $26(29)$ & $19(29)$ & 0.99 \\
\hline Urological & $5(6)$ & $7(11)$ & 0.24 \\
\hline Skin & $8(9)$ & $17(26)$ & $<0.01$ \\
\hline Other/unknown & $12(13)$ & $2(3)$ & 0.03 \\
\hline \multicolumn{4}{|l|}{ Pathogen, n (\%) } \\
\hline Gram positive & $20(22)$ & $20(30)$ & 0.26 \\
\hline Gram negative & $21(23)$ & $2 \mathrm{I}(32)$ & 0.24 \\
\hline Fungal & $5(6)$ & I (2) & 0.2 \\
\hline Mixed & $5(6)$ & $3(5)$ & 0.78 \\
\hline Unknown & $39(43)$ & $21(32)$ & 0.18 \\
\hline Medical ICU, n (\%) ${ }^{\dagger}$ & $46(5 I)$ & $26(39)$ & 0.15 \\
\hline Major bleed, n (\%) & $15(17)$ & $8(12)$ & 0.43 \\
\hline ICU length of stay; days* & $14.1 \pm 14.4$ & $27.5 \pm 30.6$ & $<0.01$ \\
\hline Hospital length of stay; days* & $17.6 \pm 16.4$ & $40.2 \pm 35.3$ & $<0.01$ \\
\hline
\end{tabular}

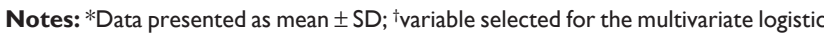
regression analysis. Vasoactive agents include: Norepinephrine, phenylephrine, epinephrine, vasopressin, dopamine, and dobutamine.

Abbreviations: APACHE, Acute Physiology and Chronic Health Evaluation; ICU, intensive care unit; CRRT, continuous renal replacement therapy; SD, standard deviation. had more organ dysfunctions $(3.3 \pm 1.1$ vs $2.9 \pm 1.2$ $P=0.04)$, and a higher APACHE II score $(30.8 \pm 5.3$ vs $28 \pm 6, P<0.01$ ) compared to survivors (Table 3 ).

Multivariate logistic regression analysis identified $\geq 3$ organ dysfunctions (OR 2.46, 95\% CI: 1.19-5.09; $P<0.05$ ) and medical ICU admission (OR 1.99, 95\% CI: 1.00-3.98; $P=0.05)$ as significant predictors of in-hospital mortality. ICU mortality was higher in patients that did not meet institutional criteria $(48 \%$ vs $64.8 \% ; P=0.05)$.

\section{Discussion}

When introducing pharmacotherapy into the clinical practice setting, institutions often implement guidelines or protocols to promote safe and efficacious use of high-risk medications. ${ }^{24}$ Institutional guidelines are useful in providing guidance to practitioners on selection of pharmacological agents with the premise of providing optimal efficacy and safety outcomes. These guidelines and protocols are based largely on available literature and package labeling, which may not provide guidance on use in high-risk patients. Data from the clinical practice setting suggest subgroups of patients receiving rhAPC therapy may be at higher risk for major bleeding and worsened outcomes. ${ }^{17}$ Although rhAPC has been withdrawn from the market, the story of its introduction, marketing, utilization in clinical practice, and removal from the market are important for clinicians involved in critical care, medication safety, and formulary decisions at the institutional level. New data and changes to package labeling makes monitoring of adherence to clinical practice guidelines and real-world outcomes essential to providing safe therapy of high-risk medications.

In this single center, descriptive study of clinical practice, patients receiving rhAPC for severe sepsis had higher mortality and major bleeding than previous published studies. ${ }^{10-17}$ Our study identified risk factors for major bleeding other than package-labeling contraindications and bleeding precautions in a diverse group of patients with severe sepsis at a tertiary academic medical center.

Utilization of rhAPC at our institution has decreased steadily since 2003 and the publication of more data from RCTs and real-world analysis. ${ }^{11,12}$ This reflects utilization in the United States, which peaked in 2005 despite marketing campaigns seeking to improve awareness of rhAPC. ${ }^{26}$ Despite use of an electronic decision support tool in our CPOE system, $34 \%$ of our cohort did not meet institutional criteria for safe use of rhAPC at baseline due to a precaution or contraindication to therapy. Use of rhAPC in patients with contraindications and bleeding precautions in the clinical 
practice has been reported to be as high as $27 \%$ in published analysis. ${ }^{15,17}$ These patients are not likely to be enrolled in large RCTs despite encompassing a large cohort of use in the clinical practice setting. Recent data suggesting these patients are at high risk of adverse reactions and worsened outcomes make data from observational studies important for clinicians seeking to evaluate safe use of rhAPC therapy at their institution.

In the current study, $14.7 \%$ of patients experienced a major bleeding event. The primary site of bleeding in our analysis was gastrointestinal, which is consistent with the primary sites in analysis from the clinical practice setting. ${ }^{15,17}$ The incidence of CNS bleed was low in our analysis $(0.6 \%)$, and was comparable to rates in RCTs and lower than many analyses from the clinical practice setting. ${ }^{10-17,27}$ The presence of a baseline precaution or contraindication to rhAPC therapy was not associated with a higher risk of bleed, suggesting package-labeling contraindications and precautions may not be protective against major bleeding events in our patient population. Differences in patient demographics, risk factors for bleeding, and definition of major bleeding may be responsible for variability in the reported bleeding rates in clinical trials and data from the clinical practice setting.

A recent analysis by Gentry and colleagues sought to examine the impact of baseline bleeding precautions on major bleeding events and outcomes in the clinical practice setting. ${ }^{17}$ Twenty of the seventy-three patients (27\%) had a bleeding precaution to rhAPC use at baseline. Patients with baseline bleeding precautions had significantly higher APACHE II scores, lower platelet concentrations, and a higher incidence of patients meeting hematological dysfunction according to the study criteria. Patients with baseline bleeding precautions had significantly higher hospital mortality and major bleeding events. Mortality in the patients experiencing major bleed was higher compared to patients not experiencing a major bleed, but failed to reach statistical significance. A second evaluation of rhAPC use in Italian ICUs found ICU mortality was significantly higher in patients experiencing bleeding. However, data on severity of illness and risk factors for bleeding was not evaluated. ${ }^{14}$

Package-labeling precautions and contraindications to rhAPC therapy stem largely from PROWESS exclusion criteria and include a platelet count $<30,000 / \mathrm{mm}^{3}$ and INR $>3.0 .{ }^{28}$ We identified baseline platelet concentrations $\leq 100 \times 10^{3} / \mathrm{mm}^{3}$ and INR $\geq 2.5$ as significant risk factors for major bleeding in our patient population using a multivariate model. Our findings suggest more conservative thresholds of baseline platelet concentrations and INR may be warranted in the clinical practice setting when evaluating the safety of rhAPC therapy.

Varying definitions of non-CNS major bleeding makes actual comparisons difficult among published analysis. PROWESS defined a serious bleeding event as "any lifethreatening bleeding, any bleeding event classified as serious by the investigator, or any bleeding that required the administration of three units of packed red cells on two consecutive days." ${ }^{10}$ The presence of a local investigator allows for a more prospective evaluation of bleeding rates and etiologies in a prospective RCT. Despite the close monitoring in RCTs, bleeding rates of rhAPC appear to be higher than analysis from the clinical practice setting. The retrospective nature of our study prohibited us from using PROWESS criteria. Similar to Gentry and colleagues, our study incorporates objective data into the retrospective diagnosis of major bleed. However, we have added to a more comprehensive retrospective evaluation by incorporating physician and nursing documentation in a progress note, discharge summary, or autopsy report to confirm the objective findings. We assessed major bleeding events during infusion and within 24 hours of discontinuation to rule out events not likely attributable to rhAPC therapy, compared to analyses that report bleeding rates from 7 to 30 days after infusion discontinuation. ${ }^{10,17}$ Despite a more objective definition, documentation requirement, and stringent window of assessment, our bleeding rates were higher than previous published analyses.

In our study, mortality rates were higher than previously reported for rhAPC therapy in RCTs, but similar to findings from the clinical practice setting. ${ }^{10-17,27}$ Higher mortality rates at our institution may be reflective of prescribing bias towards patients with higher risk of death as a result of our institutional criteria, and a higher severity of illness as seen with APACHE II and organ dysfunctions. Several analyses have examined baseline risk factors for mortality in patients receiving rhAPC therapy. The current study found $\geq 3$ organ dysfunctions and medical ICU admission as significant predictors of mortality. Significant advances in the treatment of sepsis and application of best practices has improved outcomes over the time frame of the current study, potentially limiting the ability to capture all variables associated worsened outcomes in patients receiving rhAPC therapy for severe sepsis. $^{1-4}$

There are a number of other potential limitations to our study. By not evaluating a cohort of patients with severe sepsis who did not receive rhAPC due to contraindication or 
decision of indication, it remains unclear if bleeding events that were identified were truly a result of rhAPC, or related to other comorbidities and manifestations of critical illness. The use of a computer-based institutional guideline that incorporates APACHE II calculation can introduce a prescribing bias towards patients with a high severity of illness..$^{29,30}$ However, our guideline allows attending physician override for patients with an APACHE score $<25$ or contraindications and bleeding precautions.

\section{Conclusion}

This study describes the baseline demographics, bleeding, and mortality of patients receiving rhAPC for severe sepsis at a tertiary academic medical center. Patients at our institution receiving rhAPC had higher APACHE II scores, mortality, and major bleeding events than previously published postmarketing studies. Despite a high percentage of patients having baseline precautions and contraindications to rhAPC therapy, it was not shown to be a risk factor for major bleed and mortality. Risk factors for major bleeding other than package-labeling contraindications and bleeding precautions were identified in our patient population.

\section{Disclosure}

Drs Anger, DeGrado, Greenwood, Cohen, and Szumita do not report any affiliation with or financial interest in a commercial organization that poses a conflict of interest with this article. This work was presented at the 39th Critical Care Congress of the Society of Critical Care Medicine, Miami, Florida, January 9-13, 2010. No financial support was obtained for this analysis. The protocol was reviewed and approved by the Brigham and Women's Hospital/Partners Institutional Review Board prior to data collection. Protocol \# 2009-P001304/1; BWH.

\section{References}

1. Dellinger RP, Levy MM, Carlet JM, et al. Surviving Sepsis Campaign: international guidelines for management of severe sepsis and septic shock: 2008. Crit Care Med. 2008;36(1):296-327.

2. Levy MM, Dellinger RP, Townsend SR, et al. The Surviving Sepsis Campaign: Results of an international guideline-based performance improvement program targeting severe sepsis. Crit Care Med. 2010; 38(2):367-373.

3. Ferrer R, Artigas A, Suarez D, et al. Effectiveness of treatments for severe sepsis: a prospective, multicenter, observational study. Am J Respir Crit Care Med. 2009;180(9):861-866.

4. Schorr C. Performance improvement in the management of sepsis. Crit Care Clin. 2009;25(4):857-867.

5. Yan SB, Helterbrand JD, Hartman DL, et al. Low levels of protein C are associated with poor outcome in severe sepsis. Chest. 2001;120(3): 915-922.
6. Shorr AF, Bernard GR, Dhainaut JF, et al. Protein C concentrations in severe sepsis: an early directional change in plasma levels predicts outcome. Crit Care. 2006;10(3):R92.

7. Macias WL, Nelson DR. Severe protein C deficiency predicts early death in severe sepsis. Crit Care Med. 2004;32(Suppl 5):S223-S228.

8. Levi M, van der Poll T. Recombinant human activated protein C: current insights into its mechanism of action. Crit Care. 2007;11 Suppl 5:S3.

9. Macias WL, Yan SB, Williams MD, et al. New insights into the protein $\mathrm{C}$ pathway: potential implications for the biological activities of drotrecogin alfa (activated). Crit Care. 2005;9 Suppl 4:S38-S45.

10. Bernard GR, Vincent JL, Laterre PF, et al. Efficacy and safety of recombinant human activated protein $\mathrm{C}$ for severe sepsis. $N$ Engl J Med. 2001;344:699-709.

11. Abraham E, Laterre PF, Garg R, et al. Drotrecogin alfa (activated) for adults with severe sepsis and a low risk of death. $N$ Engl J Med. 2005;353:1332-1341.

12. Vincent JL, Bernard GR, Beale R, et al. Drotrecogin alfa (activated) treatment in severe sepsis from the global open-label trial ENHANCE: Further evidence for survival and safety and implications for early treatment. Crit Care Med. 2005;33:2266-2277.

13. Bernard GR, Margolis BD, Shanies HM, et al. Extended evaluation of recombinant human activated protein $C$ United States Trial (ENHANCE US): a single-arm, phase $3 \mathrm{~B}$, multicenter study of drotrecogin alfa (activated) in severe sepsis. Chest. 2004;125(6):2206-2216.

14. Bertolini G, Rossi C, Anghileri A, et al. Use of drotrecogin alfa (activated) in Italian intensive care units: the results of a nationwide survey. Intensive Care Med. 2007;33(3):426-434.

15. Kanji S, Perreault MM, Chant C, et al. Evaluating the use of Drotrecogin alfa (activated) in adult severe sepsis: a Canadian multicenter observational study. Intensive Care Med. 2007;33(3):517-523.

16. Rowan KM, Welch CA, North E, et al. Drotrecogin alfa (activated): real-life use and outcomes for the UK. Crit Care. 2008;12(2):R58.

17. Gentry CA, Gross KB, Sud B, et al. Adverse outcomes associated with the use of drotrecogin alfa (activated) in patients with severe sepsis and baseline bleeding precautions. Crit Care Med. 2009;37(1):19-25.

18. Nadel S, Goldstein B, Williams MD, et al. Drotrecogin alfa (activated) in children with severe sepsis: A multicentre phase III randomized controlled trial. Lancet. 2007;369:836-843.

19. Sweeney DA, Natanson C, Eichacker PQ. Recombinant human activated protein C, package labeling, and hemorrhage risks. Crit Care Med. 2009;37(1):327-329.

20. Poole D, Bertolini G, Garattini S. Errors in the approval process and post-marketing evaluation of drotrecogin alfa (activated) for the treatment of severe sepsis. Lancet Infect Dis. 2009;9(1):67-72.

21. Opal SM. Can we RESOLVE the treatment of sepsis? Lancet. 2007;369(9564):803-804

22. Finfer S, Ranieri VM, Thompson BT, et al. Design, conduct, analysis and reporting of a multi-national placebo-controlled trial of activated protein C for persistent septic shock. Intensive Care Med. 2008;34(11): 1935-1947.

23. Lilly. Lilly announces withdrawal of Xigris ${ }^{\circledR}$ following recent clinical trial results. Available from: https://investor.lilly.com/releasedetail2. $\mathrm{cfm}$ ?ReleaseID=617602. Accessed October 25, 2011.

24. Fischer MA, Lilly CM, Churchill WW, et al. An algorithmic computerised order entry approach to assist in the prescribing of new therapeutic agents: case study of activated protein $\mathrm{C}$ at an academic medical centre. Drug Saf. 2004;27(15):1253-1261.

25. Eli Lilly and Co. Drotrecogin alfa (activated), Xigris: product label. Indianapolis, IN: Eli Lilly and Co; 2001.

26. Eichacker PQ, Natanson C, Danner RL. Surviving sepsis - practice guidelines, marketing campaigns, and Eli Lilly. $N$ Engl J Med. 2006;355(16):1640-1642.

27. Levi M, Levy M, Williams MD, et al. Prophylactic heparin in patients with severe sepsis treated with Drotrecogin alfa (activated). Am J Respir Crit Care Med. 2007;176:483-490. 
28. Product Information - Xigris. Eli Lilly and Co, Indianapolis, IN. 2007. Available at: http://www.xigris.com/330-safety.jsp. Accessed January 4 , 2010.

29. Greenwood B, Szumita PM, Levy H, et al. Error rates among clinical pharmacists in calculating the APACHE II score. Pharmacotherapy. 2007;27:285-289.
30. Owen PS, Tan EC, Kiser TH, et al. Reliability and accuracy of practitioner-calculated Acute Physiology and Chronic Health Evaluation II scores for determining the appropriateness of drotrecogin alfa (activated). Am J Health Syst Pharm. 2010;67(2):136-143.

\section{Publish your work in this journal}

Therapeutics and Clinical Risk Management is an international, peerreviewed journal of clinical therapeutics and risk management, focusing on concise rapid reporting of clinical studies in all therapeutic areas, outcomes, safety, and programs for the effective, safe, and sustained use of medicines. This journal is indexed on PubMed Central, CAS,
EMBase, Scopus and the Elsevier Bibliographic databases. The manuscript management system is completely online and includes a very quick and fair peer-review system, which is all easy to use. Visit http://www.dovepress.com/testimonials.php to read real quotes from published authors.

Submit your manuscript here: http://www.dovepress.com/therapeutics-and-clinical-risk-management-journal 